\title{
Printed Anchor Shaped Monopole Antenna
}

\author{
R. Seetharaman, E. Gowtham Raj \\ P. Geethanjali , S. Hariram \\ Department of ECE \\ College of Engineering -Guindy. \\ Anna University, Chennai - 600025 India.
}

\author{
M. Kannan \\ Department of Electronics Engineering \\ Madras Institute of Technology -Chromepet \\ Anna University, Chennai - 600044 India.
}

\begin{abstract}
This paper presents a printed anchor shaped antenna with a rectangular ground plane which belongs to the class of printed monopole antenna and is small $\left(20.25 \mathrm{~cm}^{2}\right)$, compact, conformal and provides an ultra wide band performance giving very good omnidirectional radiation pattern similar to monopole antenna. It has an impedance bandwidth of more than 1:7 and a constant group delay over this range.
\end{abstract}

\section{General Terms}

Printed monopole antenna, UWB antenna.

\section{Keywords}

Group delay, 3D radiation pattern, gain.

\section{INTRODUCTION}

Ultra wide band technology is the most promising solution to achieve high speed data communication. The Federal Communication Commission (FCC) regulated the emission limits of $-41.3 \mathrm{dBm} / \mathrm{Hz}$ for an allocated spectrum ranging from $3.1 \mathrm{GHz}$ to $10.6 \mathrm{GHz}$. Conventional communications involves modulation of the message signal over a high frequency carrier and then transmitting it over a channel. This is a narrowband communication scheme. UWB technology transmits message signal as pulses in time domain which occupies a large bandwidth in frequency domain. Hence the devices that would have antennas in them that can cover a wide range of frequencies are required. Moreover in UWB the messages have to be transmitted with low power to avoid interference with previously existing narrowband systems. Hence the antenna that would operate in an UWB device must be highly efficient so as to minimize the losses. As technology advances the size of devices are becoming smaller. Hence the antenna unit in these devices must be small and compact. Moreover to avoid dispersion of pulses these antennas must have a constant group delay. A constant group delay involves less dispersion in time domain. Moreover these antennas have to provide omnidirectional radiation pattern throughout the entire bandwidth.

Monopole antenna which is a modified version of the dipole provides omnidirectional radiation pattern but these are three dimensional antennas and cannot be incorporated into smaller devices [3]. If the thickness of the monopole antenna is reduced to that of a plane the resultant antennas are called planar antennas [1]-[5]. These provide a larger bandwidth than their monopole counterparts but still these are not compact enough to be incorporated into smaller devices.

Microstrip patch antennas are compact and conformal but these are inherently narrow band antennas because of their resonant nature [24]. Several techniques have been proposed in literature to enhance the bandwidth of microstrip patch antennas but these would either increase the size of the antenna or the impedance match throughout the UWB range will not be perfect [22],[24].

Printed antennas have the design of patch antennas but envisage characteristics similar to that of a monopole antenna. These are small, conformal and have a wide impedance bandwidth. Many printed antennas have been discussed in literature [6]-[22].

This paper discusses a anchor shaped printed antenna which belongs to a class of printed monopole antennas that meets the above UWB requirements. All the simulations are carried out using Ansoft HFSS software.

\section{STRUCTURE}

The geometry and coordinate system for the proposed printed monopole antenna fed by a $50 \Omega$ microstrip feed line is shown in Figure 1. It is printed on a Roger RT/ Duroid 5880(tm) substrate with a thickness of $1.6 \mathrm{~mm}$, relative permittivity of 2.2 and a dielectric loss tangent of 0.0009 . The length of the patch is $\mathrm{L}=20 \mathrm{~mm}$ and width is $\mathrm{W}=24 \mathrm{~mm}$. The width of the microstrip feed line is fixed at $\mathrm{W}_{1}=4.01 \mathrm{~mm}$ for $50 \Omega$ impedance. A rectangle of cross section $3.2 \mathrm{~mm} \times 15 \mathrm{~mm}$ is connected between the patch and the $50 \Omega$ feed line for impedance matching (quarter wave transformer). The dimensions of the feed line are shown in Figure 2.

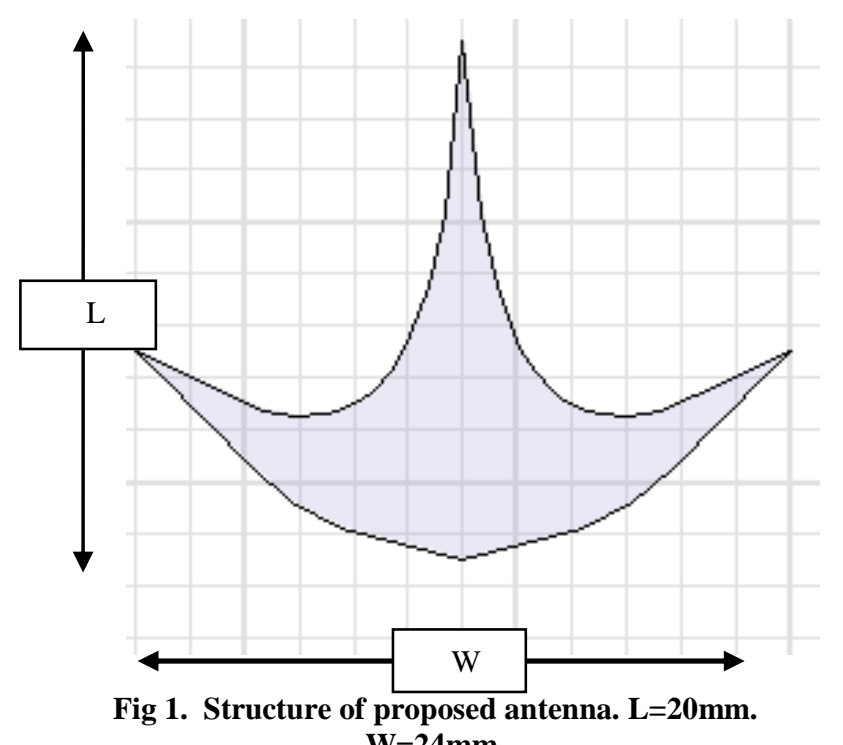

The substrate is of length $45 \mathrm{~mm}$ and width $45 \mathrm{~mm}$. The dimensions of the ground plane are $45 \mathrm{~mm} \times 14 \mathrm{~mm}$. The bottom edge of the patch is located at $3.420 \mathrm{~mm}$ above the 
ground plane. The above dimensions of the antenna are for optimum performance got as a result of extensive simulations. We found that when the patch is not center fed, for an offset feed (offset distance $f=2 \mathrm{~mm}$ ) better impedance match is obtained. This can be well understood from Figure 3 and the impedance bandwidth curves of Figure 4.

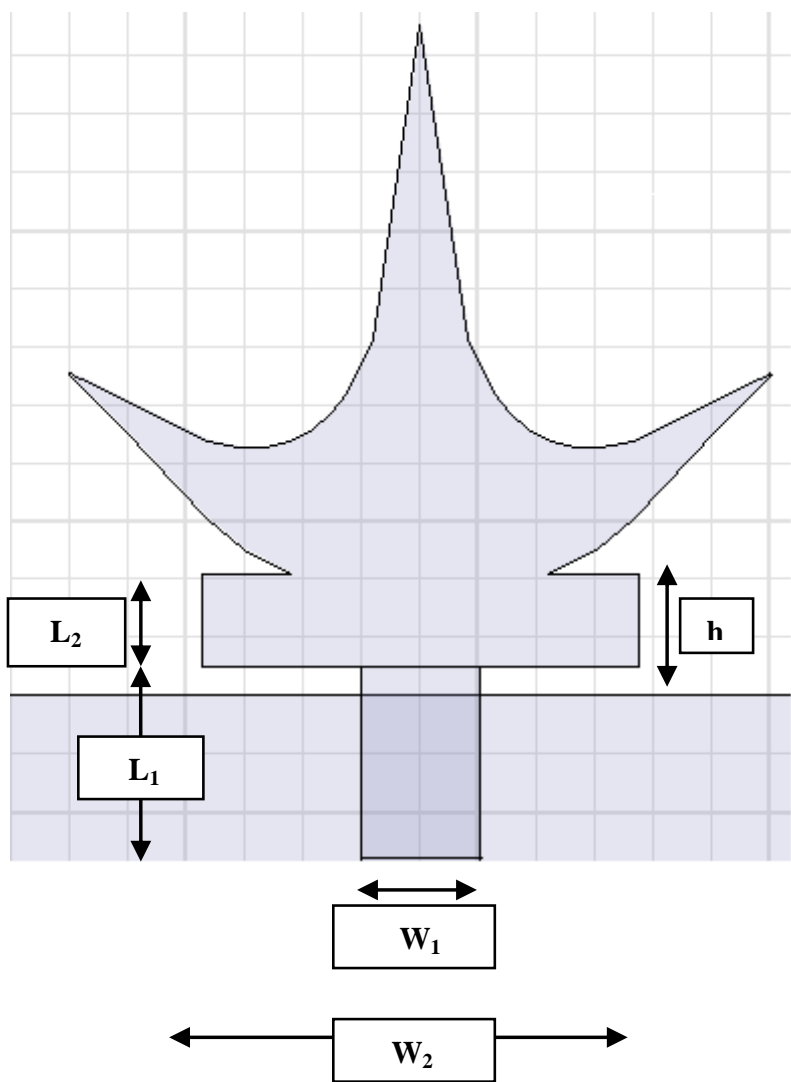

Fig 2. Dimensions of feed. $L_{1}=15 \mathrm{~mm}, L_{2}=3,2 \mathrm{~mm}$ $, W_{1}=4.01 \mathrm{~mm}, W_{2}=15 \mathrm{~mm}, \mathrm{~h}=4.2 \mathrm{~mm}$.

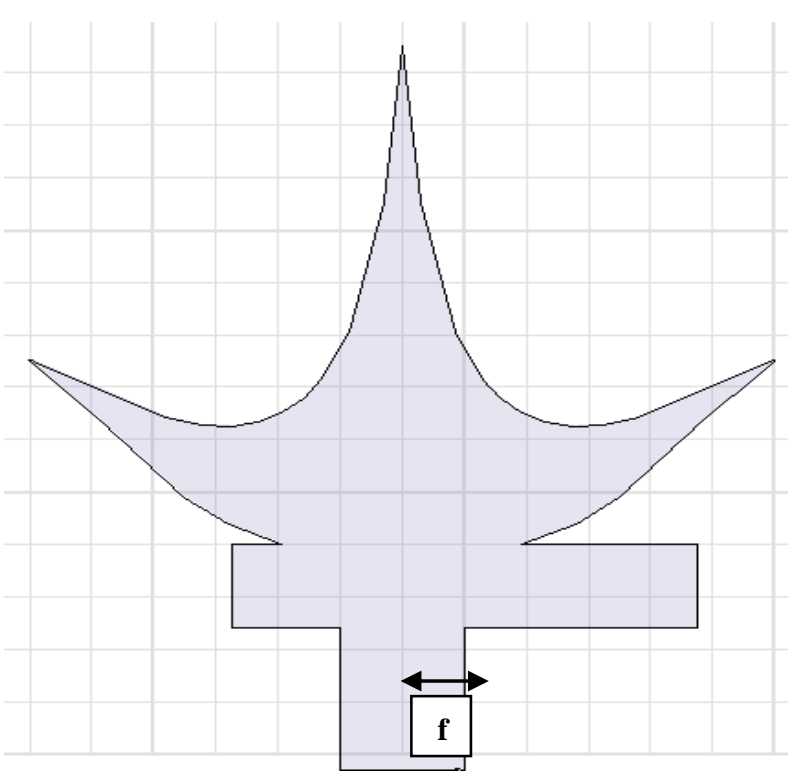

Fig 3. Offset length $f=2 \mathrm{~mm}$.

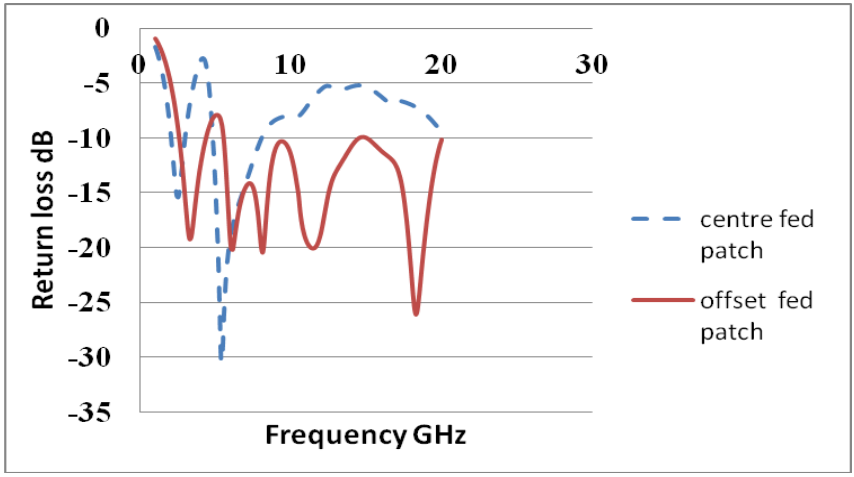

Figure 4. Impedance bandwidth curves for centre fed and offset fed patch.

\section{IMPEDANCE BANDWIDTH}

The impedance curve for the proposed antenna in which the patch is offset fed is shown in Figure 4. This Figure shows that our proposed antenna provides very good impedance match throughout the UWB range. The minima occurring in the UWB range are listed in Table 1.

Table 1. The minima occurring within the UWB range.

\begin{tabular}{|c|c|c|}
\hline Minimum & $\mathrm{f}(\mathrm{GHz})$ & Return loss $(\mathrm{dB})$ \\
\hline First & 3.28 & -19.258 \\
\hline Second & 6.23 & -20.22 \\
\hline Third & 8.12 & -20.475 \\
\hline
\end{tabular}

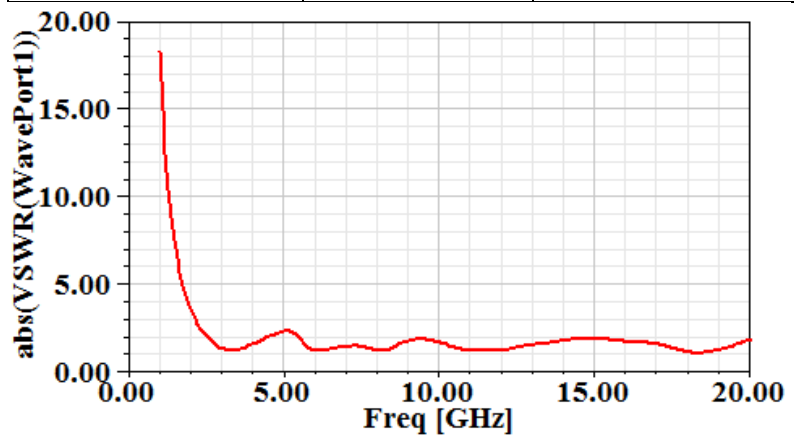

Figure 5. VSWR curve.

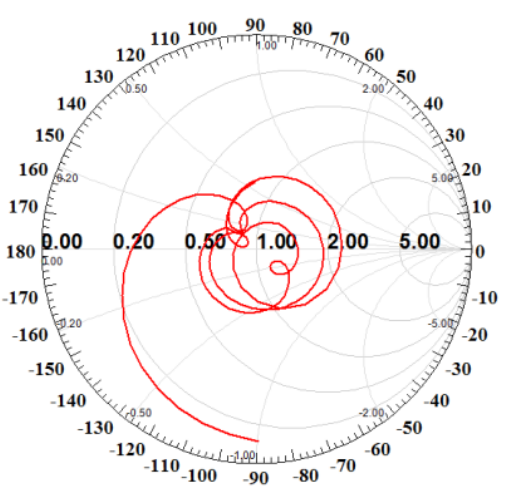

Figure 6. Smith chart showing impedance match. 
The impedance bandwidth in terms of VSWR (VSWR < 2) for is shown if Figure 5 and in terms of smith chart in Figure 6. In both the plots we see that for the UWB range there is a good impedance matching between the patch and the feed as the VSWR value is noted to be less than 2. This is also indicated by the closely packed coils in the smith chart.

\section{GROUP DELAY}

A constant group delay which ensures low dispersion in time domain is required for an UWB antenna. This is an important characteristic of an UWB antenna. The group delay graph is shown in Figure 7. From the graph we observe that the proposed antenna gives reasonably constant group delay over the UWB range.

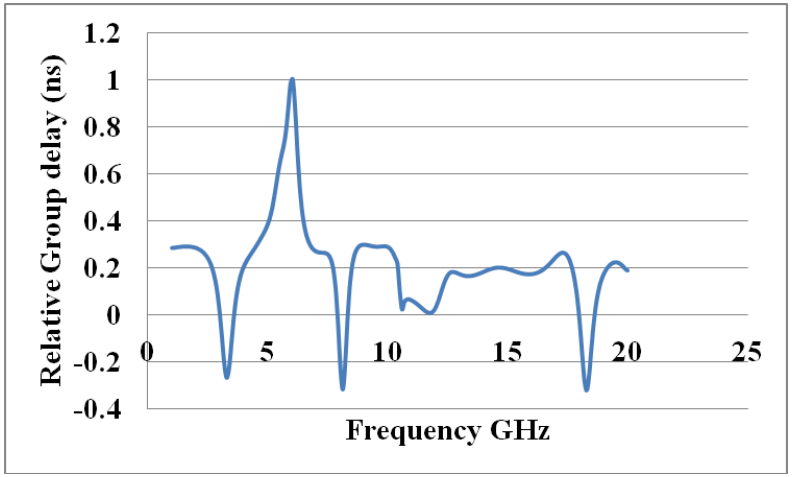

Figure 7. Relative Group delay.

\section{RADIATION PATTERN}

The radiation pattern for the various minimums listed in Table 1 is shown in Figure 11. At lower frequencies the cross polarization levels are low. As the frequency increases the cross polarization levels increase since the proposed antenna is not rotationally symmetrical. From Figure 11 we observe that this antenna provides very good omnidirectional radiation pattern throughout the UWB. The 3D radiation pattern is shown in Figure 10.

\section{GAIN}

The peak gain of the antenna for various frequencies is plotted in Figure 8. From the graph we observe that the gain gradually increases with frequency. There is a sharp increase in gain in the initial part of the graph, when the frequency reaches around $3 \mathrm{GHz}$ the sharp increase vanishes and we see a gradual increase in the peak gain value.

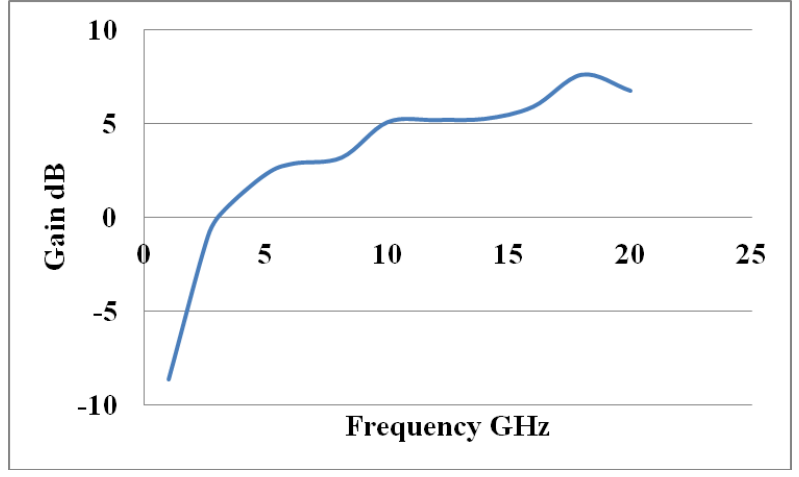

Figure 8. Gain Vs Frequency.
Gradual increase in gain indicates that there is also a gradual increase in directivity as they are directly proportional which means there is slow degradation of omnidirectional radiation pattern as the frequency increases. If there is a sharp increase in gain it would mean a sharp increase in directivity which means quick degradation of the omnidirectional radiation pattern. Our proposed antenna achieves a gradual increase in the peak gain value as shown in Figure 8.

\section{DIRECTIVITY}

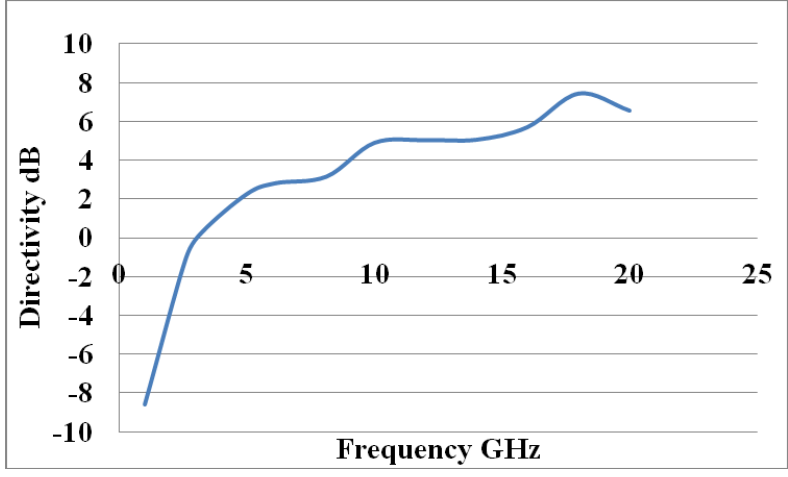

Figure 9. Directivity Vs Frequency.

High directivity means that the antenna is highly directional. Hence to get a very good omnidirectional radiation pattern the directivity value must be low. Since printed antennas are not rotationally symmetrical we would have degradation in the omnidirectional radiation pattern as the frequency increases. But the rate of degradation can be controlled. If by some mechanism we slow down the rate at which this degradation takes place then we would be getting very good omnidirectional pattern. The peak directivity for this antenna is shown in Figure 9.

From the graph we see that there is a gradual increase in directivity in the UWB region. We have a sharp increase in the directivity in the initial part of the graph, as the frequency approaches around $3 \mathrm{GHz}$ the steep increase in directivity vanishes and we have a gradual increase.

\section{3D RADIATION PATTERN}
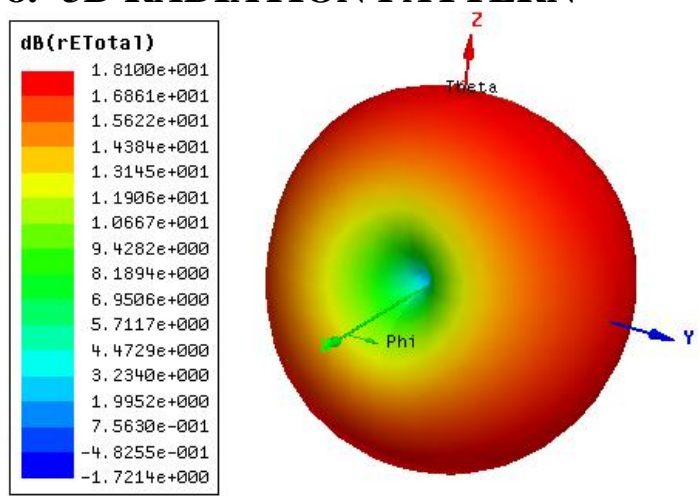

Figure 10. Three dimensional radiation pattern at 3.28Ghz. 

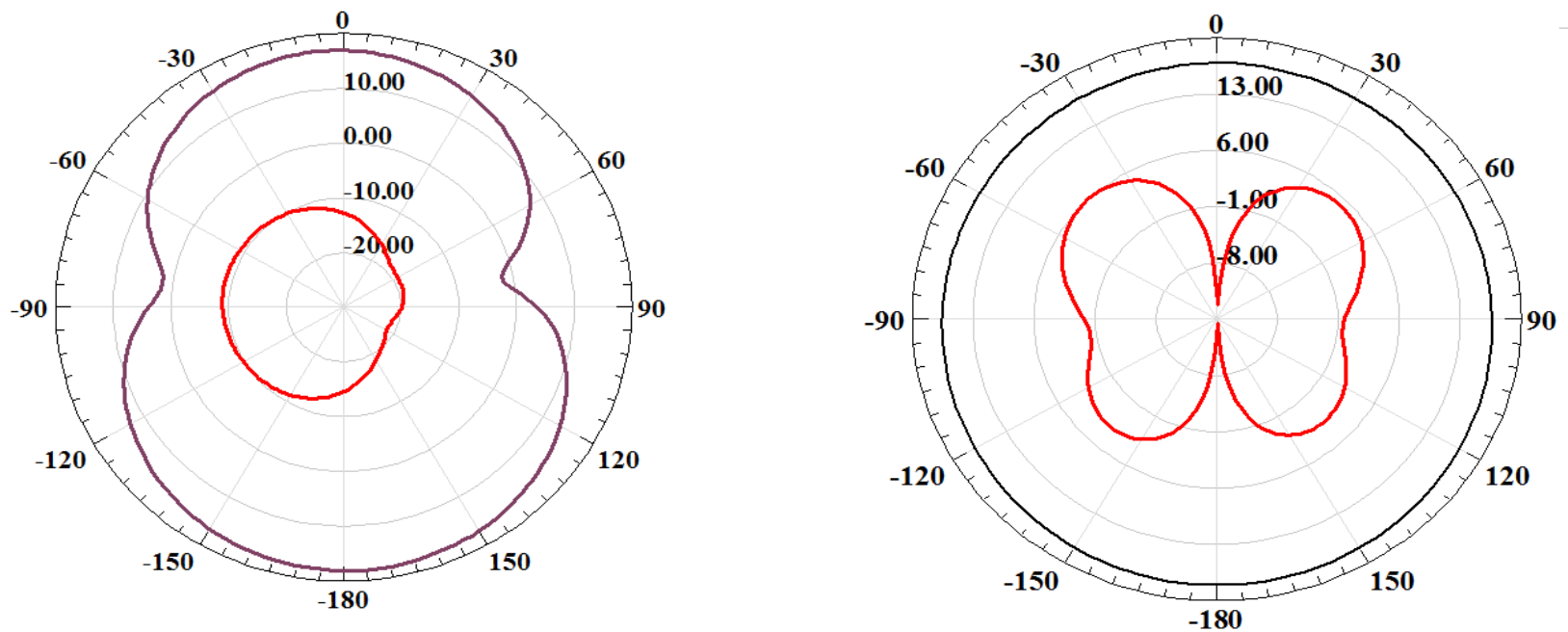

a)
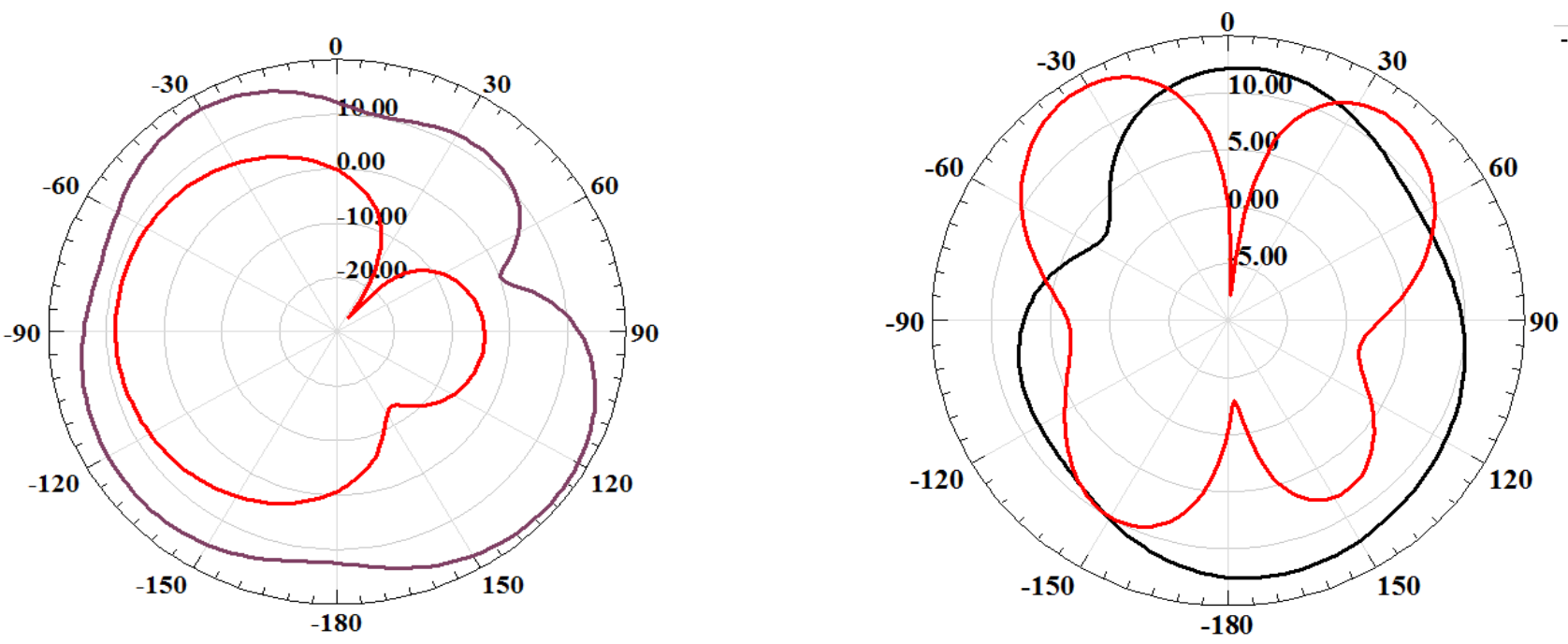

b)
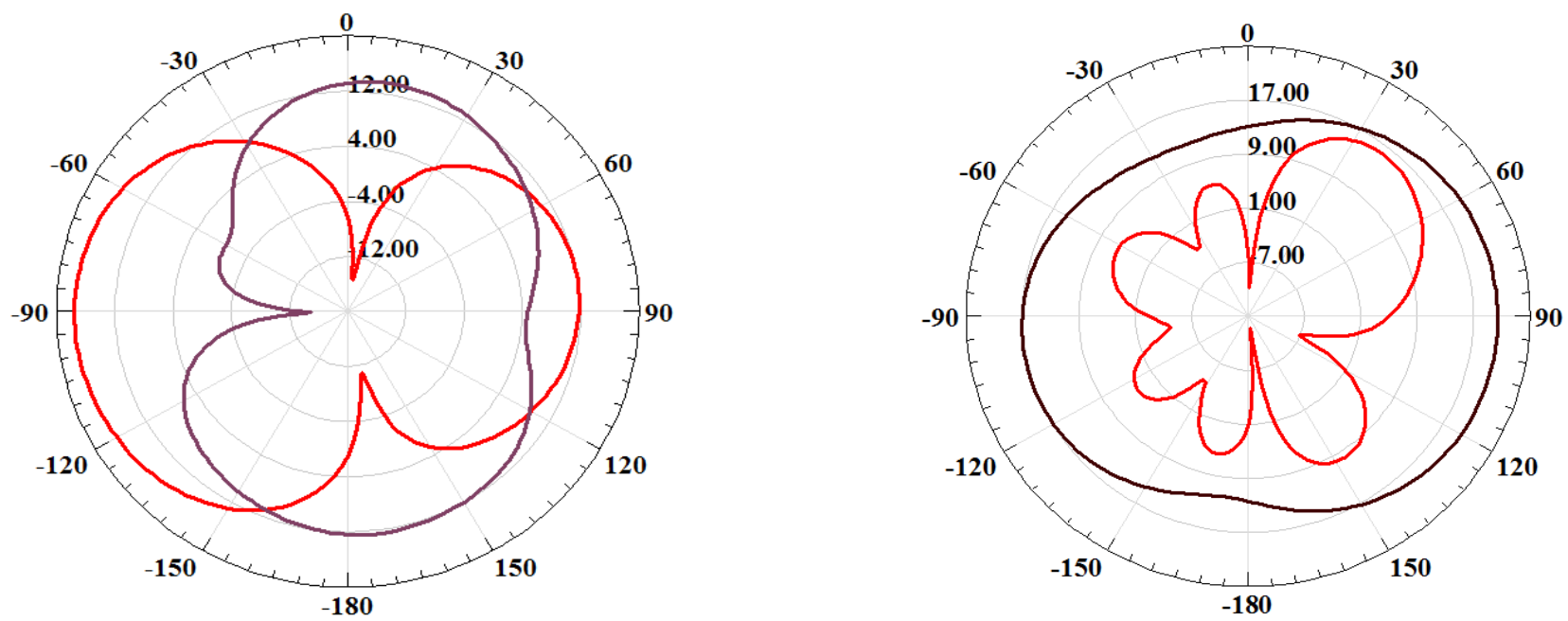

c)

YZ plane

\section{XZ plane}

Figure 11. Elevation pattern in $\mathrm{XZ}$ and $\mathrm{YZ}$ plane at a) $3.28 \mathrm{GHz}$ b) $6.13 \mathrm{GHz}$ c) $8.12 \mathrm{GHz}$. 


\section{CONCLUSION}

A printed antenna that has a shape of an anchor belonging to the class of printed monopole antenna was discussed. Its radiation pattern, impedance bandwidth, gain and directivity were analyzed. The proposed antenna is compact ( $45 \mathrm{~mm} \times 45$ $\mathrm{mm}$ ) and hence can be incorporated into smaller devices that operate in the UWB range. Since the proposed antenna operates in a very high frequency range it can be used for military purposes.

\section{REFERENCES}

[1] Xing Jian, Simin Li and Guangjie Su ," Broadband planar Antenna with Parasitic Radiator", Electronic Letters, $13{ }^{\text {th }}$ Nov 2003 , Vol 39, No 23.

[2] C.T.P. Song, Peter S. Hall and Ho GhafouriShiraz, "Shorted Fractal Sierpinski Monopole Antenna", IEEE Transactions on Antenna and Wave Propagation, Vol 52, No.10, October 2004.

[3] Seong-Youp Suh, Warren L.Stutzman and William A Davis,"A New Ultrawideband Printed Monopole Antenna: The Planar Inverted Cone Antenna(PICA)", IEEE Transactions on Antenna and Wave Propagation, Vol 52, No.5, May 2004.

[4] Zhi Ning Chen, "Broadband Roll Monopole", IEEE Transactions on Antenna and Wave Propagation, Vol 51, No.11, November 2003

[5] M.J. Ammann,Zhi Ning Chen, "Investigation on Lshaped Planar antennas", Radio Science, Vol.39, RS 2009, doi: 10. 1029/200RS3 .

[6] T.Dong, Y.P Chen "Novel Design of Ultra-Wideband Printed Double-sleeve Monopole Antenna" Progress in Electromagnetics Research Letters, Vol.9, 165-173, 2009.

[7] K.P.Ray "design Aspects of Printed Monopole Antennas for Ultra-wide band Applications" International Journal of Antennas and Propagation Vol 2008, Article ID 133858, Hindawi Publications.

[8] Kamran Ghorbani and Rod B. Waterhouse, "Ultra Broadband Printed Ultra wideband Antenna", IEEE Transactions on Antennas and Propagation, vol 50, no.12, December 2002.

[9] Abdelnasser A.Eldek, Atef Z.Elsherleni Charles E.Smith,"Wideband Modified Printed Bow-Tie Antenna with single and Dual polarization for C- and X- Band Applications" IEEE Transactions on Antenna and Wave Propagation, Vol 33, No.9, September 2005.

[10] Pengcheng Li, Jianxin Liang, Xiadong Chen"Study of Printed Elliptical/Circular Slot Antennas for Ultrawideband Applications", IEEE Transactions on Antenna and Wave Propagation, Vol 54, No.6, June 2006.

[11] Yi-Cheng Lin and Kuan-Jung Hung, "Compact Ultrawideband Rectangular Aperture Antenna and Band-Notched designs", IEEE Transactions on Antenna and Wave Propagation, Vol 54, No.11, November 2006.
[12] Wen-Shan Chen, Kuang-Yuan $\mathrm{Ku}$ "Band-Rejected Design of the printed open slot Antenna for WLAN/WiMAX operation", IEEE Transactions on Antenna and Wave Propagation, Vol 56, No.4, April 2008.

[13] Nicolas Fortino, Jean-Yves Dauvignac, Gerges Kossiavas and Robert Staraj, "Design Optimization of UWB Printed Antenna for Omnidirectional Pulse Radiaton", IEEE Transactions on Antenna and Wave Propagation, Vol 56, No.7, July 2008.

[14] Reza Zaker, Changiz Ghobadi and Javad Nourinia, “ Bandwidth Enhancement of Novel Compact Single and Dual Band -Notched Printed Monopole Antenna with a pair of L-shaped slots", IEEE Transactions on Antenna and Wave Propagation, Vol 57, No.12, December 2009.

[15] Nan Chang and Jing-Hae Jiang, "Meander Tshaped Monopole Antenna", IEEE Transactions on Antenna and Wave Propagation, Vol.57, N0.12, December 2009.

[16] K. Gerorge Thomas and M.Sreenivasan, "A simple Ultra Wideband Planar Rectangular Printed Antenna with Band Dispensation", IEEE Transactions on Antenna and Wave Propagation, Vol 58, No.1, January 2010.

[17] Jianjun Liu, Shunshi Zhong Karu P. Esselle,” A Printed Elliptical Monopole Antenna with Modified Feeding Structure for Bandwidth Enhancement" IEEE transactions on Antenna and Propagation, vol.59, No.2, Feb 2011 .

[18] M.Ojaroudi, Sh. Yazadanifard, N.Ojaroudi, and M.Naser-Moghaddasi," Small square Monople Antenna with Enhanced BandWidth by using Inverted T-shaped slot and Conductor-Backed Plane", IEEE Transactions on Antenna and Propagation, vol.59,No.2,Feb 2011.

[19] Mohamed Nabil Srifi, Symon K Podilchak, Mohamed Essaidi, Yahia M.M. Antar, "Compact Disc Monopole Antennas for Current and Future Ultrawideband (UWB) Applications, IEEE Transactions on Antenna and Propagation, Vol 59, No.12, December 2011.

[20] Rod.B. Waterhouse, S.D/ Targonski, D.M.Kokotoff, "Design and Performance of Small Printed Antennas" IEEE Transactions on Antenna and Propagation, Vol.46, No.11, Nov 1998.

[22] Rajender Singh, "Broadband Planar Monopole Antennas" M.tech Credit Seminar Report, Electronic Systems group, Electrical Department, IIT Bombay, November 2003

[23] Karlo Costov and Victor Dimitriev., "Planar Monopole Antenna with cuts at the edges and Parasitic Loops,". Ultra wide band communications Novel trendsAntennas and Propagation, Federal University of Para Brazil.

[24] "Broadband Planar Antennas Design and Applications" Zhi Ning Chen and Michael Y.W. Chia. John Wiley \& Sons, Ltd. 